\title{
Design of A Low-Cost Simulator for Auscultation Training
}

\author{
P Sánchez González ${ }^{1,2 *}$, J Rubio ${ }^{3}$, P Rubio¹ ${ }^{1}$ I Oropesa ${ }^{1}$, M Quintana ${ }^{3}$ and EJ Gómez ${ }^{1,2}$ \\ ${ }^{1}$ Biomedical Engineering and Telemedicine Centre, ETSI Telecomunicación, Center for Biomedical Technology, Universidad Politécnica \\ de Madrid, Spain \\ ${ }^{2}$ Centro de Investigación Biomédica en Red en Bioingeniería, Spain \\ ${ }^{3}$ Instituto de Investigación Hospital Universitario La Paz, Spain \\ *Corresponding author: P Sánchez González, Biomedical Engineering and Telemedicine Centre, ETSI Telecomunicación Center for \\ Biomedical Technology, Universidad Politécnica de Madrid, Madrid, Spain
}

\begin{tabular}{|c|c|}
\hline ARTICLE INFO & ABSTRACT \\
\hline Received: 幽 October 20, 2019 & The stethoscope is a daily instrument in clinical practice of any healthcare \\
\hline Published: 㟽 October 31, 2019 & $\begin{array}{l}\text { professional. The incorporation of simulators can be a useful tool to allow professionals } \\
\text { to train auscultation skills. This paper presents a wireless auscultation device that allows }\end{array}$ \\
\hline
\end{tabular}

Design of A Low-Cost Simulator for Auscultation Training. Biomed J Sci \& Tech Res 22(3)-2019. BJSTR. MS.ID.003743.

\section{Introduction}

Education of healthcare professionals is one of the major contributors for patient safety. Cardiac auscultation is one of the most important physical examination skills, providing useful information to diagnose patients with a variety of cardiac and pulmonary diseases [1]. Auscultation requires both theoretical knowledge and practical experience, making it a complex technique to master. Although the stethoscope is routinely used by healthcare professionals, the acquisition of the required skills is not straightforward during undergraduate training. For this reason, it is necessary to exercise listening skills in order to recognize different sounds of the body in order to make a right diagnosis and long periods of practice with patients are needed. Prior to becoming engaged with real patients, it is important that learners be taught in classrooms or using simulators. Pre-recorded lung sounds have been used to teach sound recognition for many years, with limited effectiveness. Simulators have been proved to improve safety (learner and patient), and to impact quality in medical practice [2]. This paper presents a novel low-cost simulator for auscultation training.

\section{Materials and Methods}

The proposed simulator allows the training of the auscultation technique thanks to the incorporation of two components: hardware and software. Both modules exchange the information necessary for the reproduction of the sounds corresponding to different use cases. The simulator starts working after the selection of a clinical case. The case is described explaining the didactic objective and then the user can interact with the hardware module touching the different sensors and then listening the corresponding sounds.

\section{Hardware}

The stethoscope simulator hardware components are shown in Figure 1. The stethoscope is built removing the olives and replacing them with wireless headphones. These headphones are connected via Bluetooth to the software component (where sounds are played). In this way, the sounds are heard as if they were part of the stethoscope. The auscultation foci device is composed of force-pressure sensors distributed over the thoracic cavity of a mannequin. 
The sensors detect when the bell is positioned on them and the pressure that is being exerted on these points (for differentiating between lung and/or heart sounds). These values are sent to the software component through an ESP8266 Wi-Fi microchip. Finally, a battery is incorporated to power the board and allows the device to not depend on any connection that could limit the movement of the person performing the simulation. This makes the implemented device wireless and provides fidelity to the reproduction of cases.
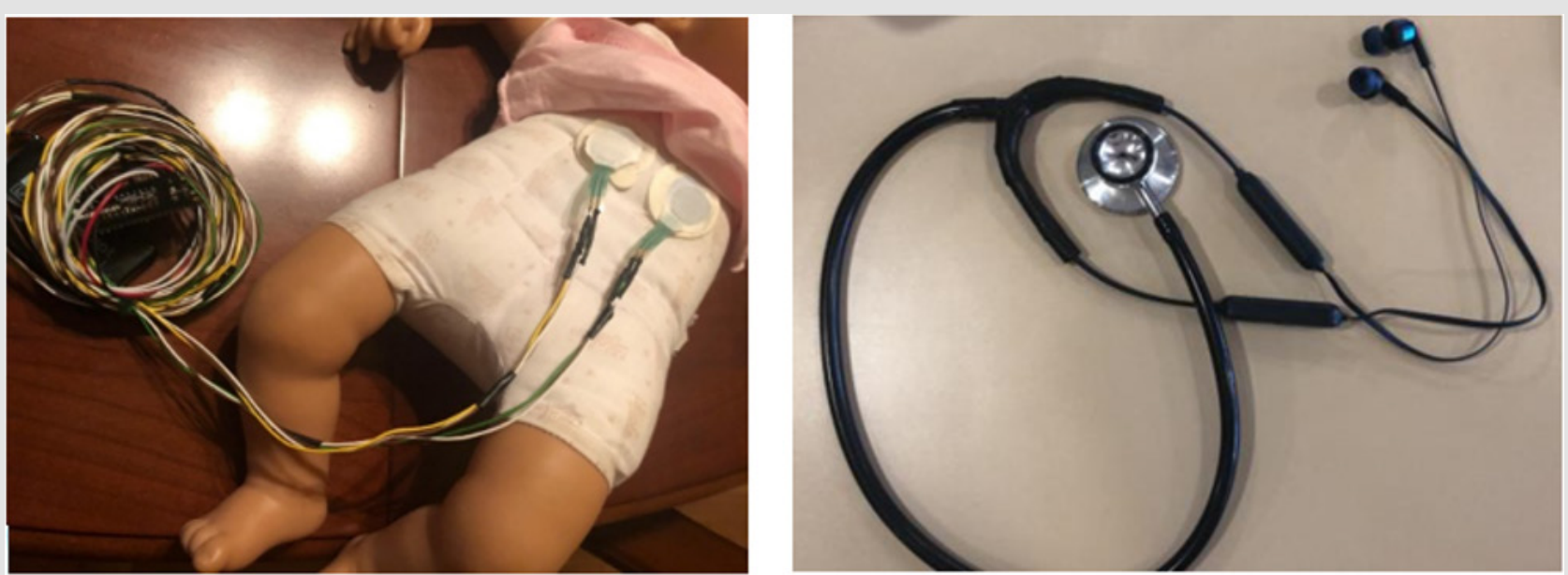

Figure 1: Hardware Simulator components: (Left) Stethoscope; (Right) Auscultation foci device.

\section{Software}

The software is composed by three main components: user interface, server and data bases that manage users and clinical use cases. Figure 2 shows the main user interface of the simulator, where the selected use case is described, and trainees listen the corresponding sounds depending on the sensors touched.

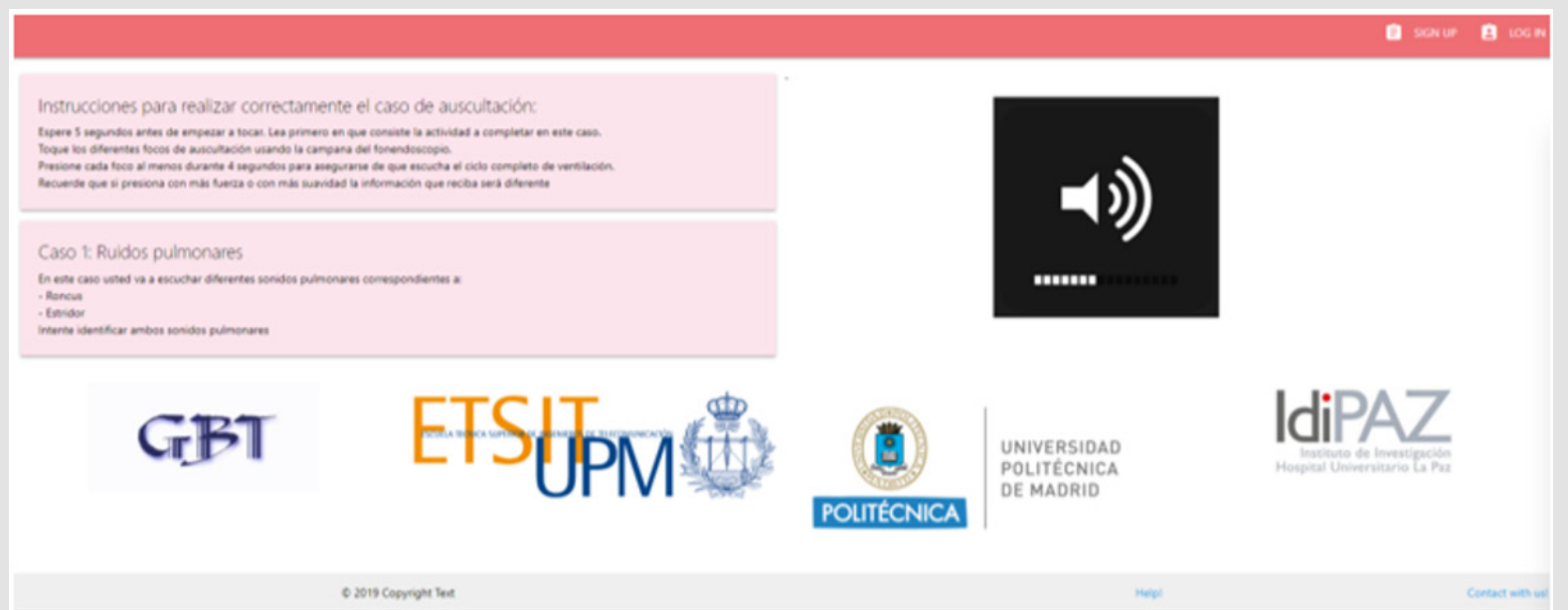

Figure 2: Simulator user interface.

\section{Validation}

Usability validation was carried out based on the free use of the simulator. A System Usability Scale (SUS)-based questionnaire was used to identify its strengths and weaknesses. Interviews were also conducted to complement the results.

\section{Results}

Seven users ( 5 trainees, 2 professors) have tested the prototype. SUS results are shown in Figure 3. A good acceptability range has been achieved, with an overall SUS score of 83.2. During interviews, users pointed out that the simulator allowed them to practice the auscultation technique and to train the required skills. Another important aspect highlighted by participants was its potential use for objectively assessing skills.

\section{Conclusion}

A novel simulator for auscultation training has been presented. Future works include the incorporation of new use cases to train different pathologies and a validation including more clinicians. Its incorporation into different training activities is planned for the coming months. 


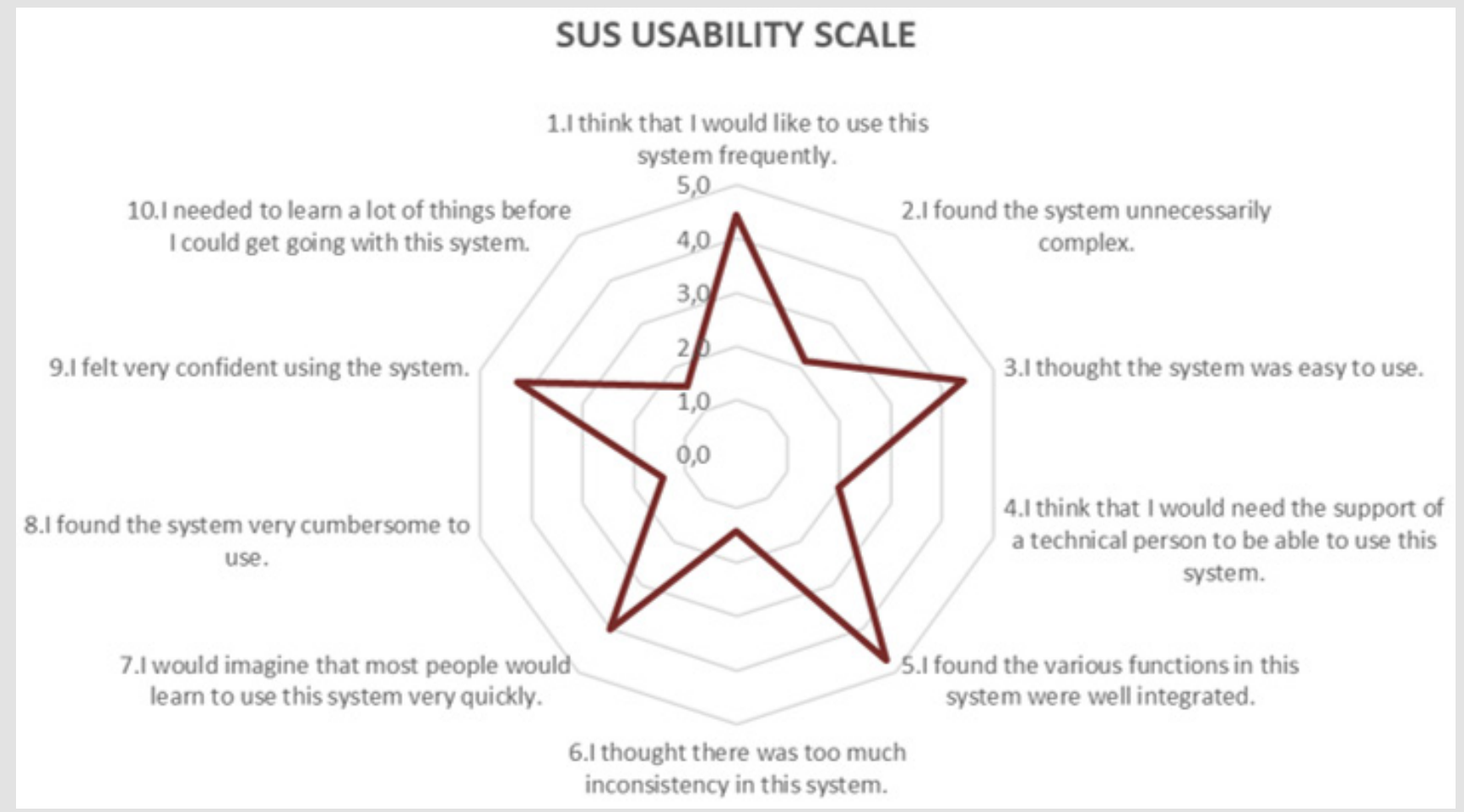

Figure 3: Validation results.

\section{References}

1. JC Fang, PT OGara (2015) The history and physical examination: an evidence-based approach DL Mann, DP Zipes, P Libby, Bonow RO (Eds.). Braunwald's heart disease $\left(10^{\text {th }}\right.$ edn.). Elsevier Saunders, Philadelphia, USA, pp. 95-113.

\section{ISSN: 2574-1241}

DOI: $10.26717 /$ BJSTR.2019.22.003743

P Sánchez González. Biomed J Sci \& Tech Res

(C) (P) This work is licensed under Creative

Submission Link: https://biomedres.us/submit-manuscript.php
2. H Al Elq Abdulmohsen (2010) Simulation-based medical teaching and learning. J Family Community Med 17(1): 35-40.

$\begin{array}{ll}\text { BIOMEDICAL } & \text { Assets of Publishing with us } \\ \text { RESEARCHES } & \text { - Global archiving of articles } \\ \text { - Immediate, unrestricted online access } \\ \text { - Rigorous Peer Review Process }\end{array}$

